\title{
USO DE MÚSICA PARA O ENSINO DE INGLÊS COMO LÍNGUA ESTRANGEIRA EM UM AMBIENTE BASEADO EM CORPUS
}

\author{
Maria Claudia Nunes Delfino \\ Doutoranda em Linguística Aplicada e Estudos da Linguagem pela Pontifícia Universidade \\ Católica de São Paulo (PUC-SP) \\ claudia@fatecpg.com.br
}

\section{RESUMO}

Poucos trabalhos lançam mão de banco de dados musicais baseados em corpora para o desenvolvimento de atividades que corroboram o ensino-aprendizagem de uma segunda língua. O objetivo desse artigo é preencher essa lacuna por meio de um corpus composto de aproximadamente 150 mil palavras, de 585 letras de música dos artistas Beatles, Bon Jovi, Maroon 5 e Bruno Mars. As análises e as investigações para a criação dos exercícios usam dimensões de variação, colocações, coligações, palavraschave, entre outros aspectos abordados pela Linguística de Corpus. Entrevistas foram realizadas com os alunos para descobrir a percepção que eles tinham das aulas.

Palavras-chave: Linguística de Corpus; Ensino de Língua Inglesa como Língua Estrangeira; música; Análise Multidimensional.

\begin{abstract}
Few researches use music corpus to develop activities which corroborate the teaching and learning of a foreign language. The aim of this article is to fill this gap through a corpus composed of around 150,000 words from 585 British and American lyrics from pop songs performed by the following artists: Beatles, Bon Jovi, Maroon 5 and Bruno Mars. The analysis to create the exercises use dimensions of variation, collocations, coalitions, key words among other aspects addressed by Corpus Linguistics. Interviews of the students were conducted on an attempt of throwing light onto the process of learning English in a corpus-based environment.
\end{abstract}

Keyworks: Corpus Linguistics; Teaching of English as a Foreign Language; songs; Multidimensional Analysis. 


\section{Introdução}

A importância da música de língua inglesa no ensino-aprendizagem de inglês como língua estrangeira (ILE) tem sido estudada por vários autores, tais como Domoney e Harris (1993) e Little (1983), que verificaram que a maior fonte de contato de um aprendiz de inglês com a língua, fora da sala de aula, parece ser a música. Porém, aulas de inglês tendo a música como elemento central não são tão frequentes em aulas de língua inglesa. O que é comum são exercícios utilizando a letra de música como algo à parte da aula, num momento de descontração no início ou no final da lição. Esta pesquisa, de maneira alternativa, busca utilizar letras de música na forma de exercícios para o ensino da língua inglesa. As metodologias utilizadas na confecção de tais exercícios são proporcionadas pela Linguística de Corpus (LC) para relacionar a música ao ensino da língua inglesa.

O intuito deste artigo é oferecer uma prática alternativa e inovadora ao emprego de música nas salas de aula presenciais de ILE, utilizando diferentes mídias além de exercícios impressos e do áudio com a música, tais como sites da internet e programas computacionais, fornecendo possibilidades de o aluno fazer pesquisas de forma mais autônoma, sem receber tudo pronto das mãos do professor. Apesar de a grande maioria dos professores de idiomas já utilizar a música na sala de aula, em geral, não há muita variedade. As atividades concentram-se, basicamente, em exercícios nos quais o aluno é requisitado a preencher espaços em branco enquanto ouve a música, ou a colocar versos da música na ordem correta, não suscitando a autonomia por meio da investigação e descoberta de padrões de linguagem, que é o 
que objetivamos neste trabalho por meio de atividades elaboradas a partir da língua em uso.

Para tanto, existem cinco pontos a serem abordados para a confecção de tais exercícios, quais sejam: a visão de linguagem a partir dos pressupostos da LC, o uso de corpora na sala de aula, os objetivos da pesquisa, o corpus utilizado e sua aplicação em tais exercícios.

Primeiro, apresentaremos a visão de linguagem da LC, que faz uso de uma abordagem empirista, segundo a qual o conhecimento se origina da experiência, oferecendo uma proposta calcada em atividades elaboradas a partir da língua em uso voltadas para o ensino e aprendizagem. A linguagem é vista como um sistema probabilístico para a LC (BERBER SARDINHA, 2004); ou seja, pressupõe-se que os traços linguísticos não ocorrem de forma aleatória. Desse modo, é possível evidenciar e quantificar regularidades (padrões) existentes entre os traços linguísticos e os contextos situacionais de uso da linguagem. Dependendo da situação na qual a linguagem está inserida, certos traços são mais frequentes que outros (HOEY, 2000).

A partir desses pressupostos, Berber Sardinha (2010) apresenta maneiras de se usar corpora em sala de aula por meio de concordâncias. O autor propõe três tipos de atividades para o ensino de ILE: centradas na concordância, centradas no texto e multimídia/multigênero. As atividades centradas na concordância focam na identificação dos padrões lexicogramaticais e, para a sua consecução, são sugeridos exercícios acompanhando as concordâncias, modelo o qual também seguiremos, como será observado nas seções seguintes. O segundo tipo de atividade parte de um texto e trabalha as questões que o envolvem, como tema, gênero, ideias principais, além de 
trazer concordâncias com palavras encontradas no texto. De maneira similar, utilizamos tal ponto de vista, uma vez que propomos exercícios em que os alunos usam a letra da música da qual provém o nódulo estudado, e não apenas as linhas de concordância. Por seu turno, as atividades multimídia/multigênero envolvem diferentes mídias e gêneros e incentivam o aluno a entender as diferenças entre eles e seus padrões frequentes ou típicos levantados por meio dos resultados obtidos com a análise multidimensional, metodologia que permite comparar registros diversos em diferentes dimensões linguísticas. Tal recurso multimídia está igualmente embutido em nossa proposta, já que o aluno, para desenvolver alguns exercícios, faz uso de mídias diversas.

A motivação em produzir materiais didáticos que pudessem estimular o estudante a querer aprender mais com a música em sala de aula, por meio da pesquisa com corpus, deu origem ao objetivo principal deste artigo. A música pode motivar o aluno a tornar-se responsável pela construção de seu conhecimento, ou seja, a ensejar sua independência em relação ao professor.

Porém, para que sejam observados os padrões de linguagem contidos na música, antes de tudo é preciso organizar e coletar um corpus que represente um conjunto de letras de música. De acordo com Berber Sardinha (2004), corpus é definido como um conjunto de dados linguísticos que segue alguns critérios, e que são suficientemente extensos para poderem ser processados por computador para sua descrição e análise.

O critério utilizado de seleção e coleta de música do corpus foi a proximidade da música de língua inglesa com o universo do aluno. Desse modo, desde o começo da 
pesquisa, os alunos foram participativos e votaram nas bandas e cantores cujas músicas eles gostariam de estudar em sala de aula.

Para aplicação dos exercícios desenvolvidos para esta pesquisa, a pesquisadora montou um curso de inglês extracurricular embasado nos pressupostos da LC e letras de música como fonte do material didático. As aulas ocorriam semanalmente, com duração que variava de uma a duas horas, dependendo da quantidade de exercícios e do nível de dificuldade apresentado em cada bloco de exercícios.

\section{A música e a Linguística de Corpus}

Pode-se dizer que em uma aula de inglês, é aconselhável que o aprendiz esteja em contato com o vocabulário fundamental da língua, maximizando o desempenho dos alunos em sala de aula. No caso das músicas, a prática da língua falada, juntamente com as informações advindas de corpus, pode propiciar bons resultados, já que as letras de música são textos escritos para serem cantados (falados, uma espécie de diálogo) e que exibem padrões observáveis de regularidade que podem ser usados para ensinar a língua inglesa (BERTÓLI-DUTRA, 2010, p. 2).

A referida autora (2002) sugere modelos de atividades para o uso de letras de música em inglês para o ensino de vocabulário temático, assim como aspectos gramaticais da língua, além de apresentar atividades que enfocam padrões formados por conjunções. Veirano Pinto (2014) utiliza a música para o ensino de linking sounds, combinações sonoras que podem ocorrer entre a última sílaba de uma palavra e a primeira de outra na língua inglesa. A autora da presente pesquisa inspirou-se nesta 
obra, partindo do pressuposto que ambas as autoras utilizam a letra de música como elemento central da aula, mas buscaram recursos em buscadores da internet. $\mathrm{Na}$ presente pesquisa, frases de variadas letras de música, presentes no corpus eleito pelos alunos, foram utilizadas como exemplos, deixando mais explícito que mesmo quando os exercícios da aula não eram baseados em uma única letra de música, eles, ainda assim, envolviam músicas do universo eleito pelos alunos.

Frente ao exposto, esta pesquisa busca mostrar que as letras de música abrigam palavras comuns e espelham, guardadas as devidas proporções, a língua falada em diversas situações sociais. A música pode oferecer a oportunidade ao aprendiz de tornar-se responsável pelo seu aprendizado, por permitir um ganho lexicogramatical e a capacidade de refletir sobre a língua usada no mundo real.

Exercícios didáticos, elaborados a partir de investigação baseada em corpus, podem ajudar no entendimento linguístico, pois o aluno começa a trabalhar não apenas com palavras isoladas, mas também com blocos que andam juntos em determinadas situações. Ademais, as informações obtidas desse entrelaçamento de música e LC podem servir para a elaboração de materiais didáticos mais relevantes, expressando, assim, a linguagem autêntica.

\section{Metodologia}

O gráfico abaixo mostra de maneira sintética todos os passos utilizados na metodologia: 
Gráfico 1 - Síntese de procedimentos e ferramentas usados na pesquisa

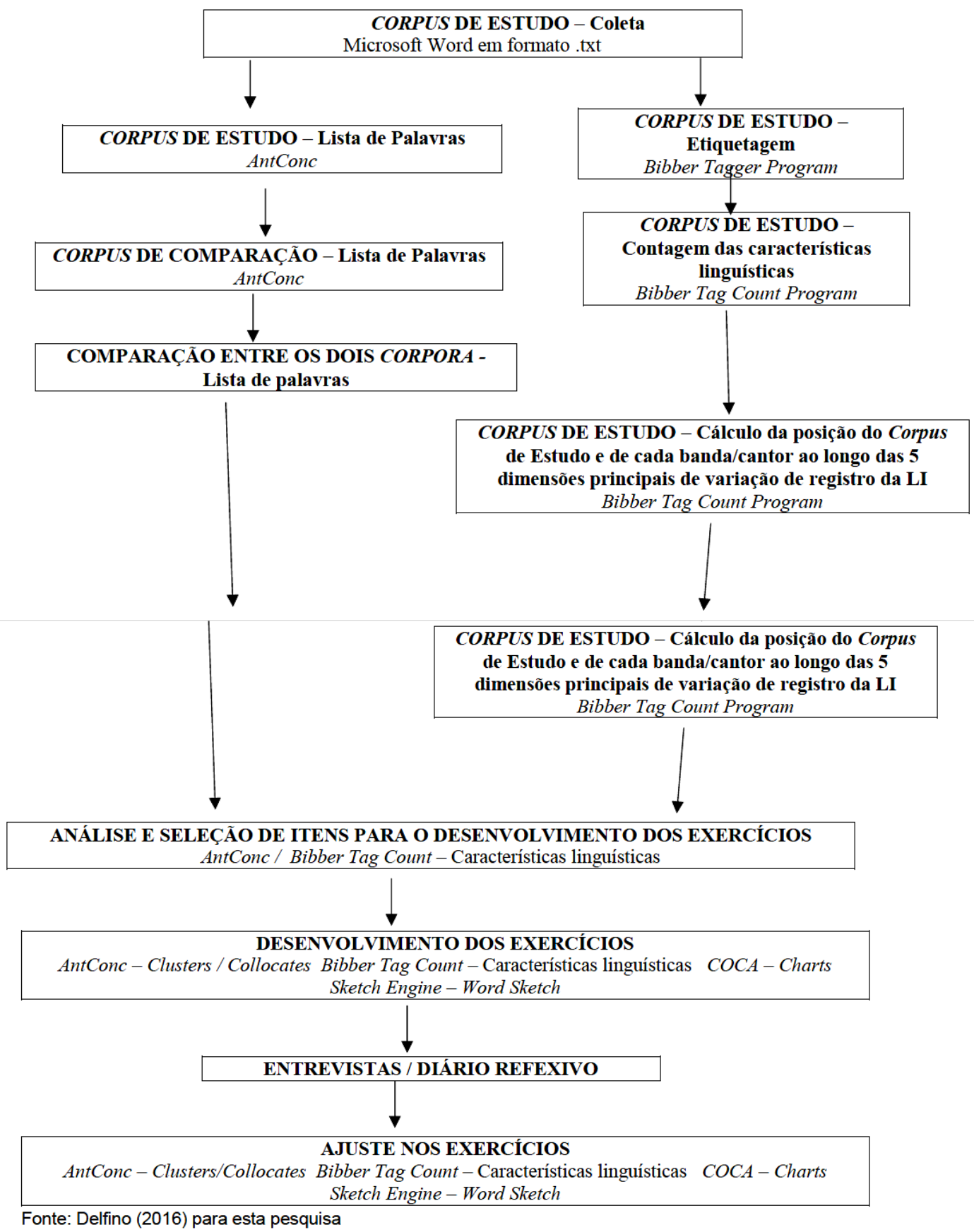

Os dados que compõem esta pesquisa são formados por um corpus composto de letras de todas as músicas das bandas Beatles, Bon Jovi e Maroon 5 e do cantor Bruno Mars, o que perfaz aproximadamente 150.000 palavras. Este corpus foi considerado o corpus de estudo, coletado a partir das letras colocadas no site oficial 
das bandas e do cantor até janeiro de 2014. A Tabela 1, a seguir, mostra detalhes do corpus CoEL.

Tabela 1 - Composição do CoEL

\begin{tabular}{|l|c|c|}
\hline \multicolumn{1}{|c|}{ Subcorpus } & Músicas & Palavras \\
\hline CoEL Beatles & 202 & 34.888 \\
\hline CoEL Bon Jovi & 220 & 59.964 \\
\hline CoEL Bruno Mars & 92 & 30.593 \\
\hline CoEL Maroon 5 & 71 & 21.211 \\
\hline CoEL & 585 & 154.487 \\
\hline
\end{tabular}

Fonte: Delfino (2016)

As músicas foram coletadas nos sites oficiais das bandas', com exceção da banda Maroon 5. O site oficial da referida banda possuía menos canções do que o site Vagalume e, por essa razão, a pesquisadora optou por coletar as letras do referido site. A partir daí, os dados foram tratados de forma que mantivessem a mesma formatação. Em suma, todos os dados foram arquivados retirando-se o título das canções - uma vez que se considera que eles não fazem parte integrante da letra assim como qualquer figura, atalho ou qualquer outro componente que não seja palavra, e foram salvos no formato .txt (texto sem formatação) - pois esse é o formato requerido para o processamento dos dados no programa computacional AntConc, versão 3.2.4w (ANTHONY, 2011).

Além do mencionado corpus CoEL, a pesquisa empregou um corpus de 
comparação, que vem a ser um corpus representativo da língua que está em constante atualização e pode ser utilizado para contrastar com o que é encontrado na língua em uso com os achados de um corpus menor, como fizemos nesta pesquisa. O corpus de comparação utilizado para esta pesquisa foi o Corpus of Contemporary American English (COCA), com 520 milhões de palavras, distribuídas em 220.225 textos coletados entre 1990 e 2015, distribuídos igualmente entre cinco registros, a saber: falado, ficção, revista, jornal e acadêmico, sendo 20 milhões de palavras por ano (DAVIES, 2015).

\subsection{Análise dos padrões}

Os dados foram analisados conforme descreve-se a seguir. Primeiramente, foi realizada a extração de listas de palavras do corpus de estudo, o CoEL, com auxílio do programa computacional AntConc. Depois, foi feita a comparação manual das 100 palavras mais frequentes do corpus de estudo com o corpus de comparação, o COCA.

A partir dos dados obtidos nesta comparação, o corpus de estudo foi rodado no programa AntConc, no qual linhas de concordância foram extraídas, revelando padrões a serem utilizados nos exercícios. O Quadro 1, abaixo, ilustra exemplos de linha de concordância do corpus CoEL com a palavra nódulo BUT, a 21a mais frequente no corpus de estudo, e 26ạ colocada na lista de frequência do corpus de comparação.

Quadro 1 - Linhas de concordância de but do corpus de estudo 


\begin{tabular}{|l|l|}
\hline$\underline{1}$ & $\underline{\text { Oh, now but every girl I've ever had }}$ \\
\hline$\underline{2}$ & $\underline{\text { Every day I've done nothing but cry }}$ \\
\hline$\underline{3}$ & $\underline{\text { It's not the same but I am to blame, it's to plain to }}$ \\
\hline$\underline{4}$ & $\underline{\text { she'll always be the only girl for me. }}$ \\
\hline$\underline{5}$ & $\underline{\text { Best of times become }}$ \\
\hline$\underline{6}$ & $\underline{\text { desperation but how many tears must }}$ \\
\hline$\underline{7}$ & $\underline{\text { You can run but you can't hide }}$ \\
\hline$\underline{8}$ & $\underline{\text { Just seventeen but you act full grown }}$ \\
\hline$\underline{9}$ & $\underline{\text { Same bed, but it feels just a little bit bigger now }}$ \\
\hline$\underline{10}$ & $\underline{\text { Our song on the radio, but it don't sound the same }}$ \\
\hline$\underline{11}$ & $\underline{\text { Now my baby is dancing, but she's dancing with another }}$ \\
\hline$\underline{12}$ & $\underline{\text { To try and apologize for my }}$ \\
\hline & $\underline{\text { mistakes but I just want you }}$ \\
\hline
\end{tabular}

Fonte: Delfino (2016)

Exercícios com linhas de concordância, como as ilustradas no quadro acima, foram usados para o trabalho com os padrões, significados e até mesmo para predição, nas quais o aluno comparava suas hipóteses a respeito de um padrão ou significado com o posterior estudo das linhas. O trabalho com as linhas de concordância esteve alinhado aos princípios da proposta Multimídia / Multigênero de Berber Sardinha (2011), uma vez que o aluno é levado a criar suas próprias hipóteses com base na 
análise das linhas e a construir o conhecimento a partir de observações, como em um trabalho de pesquisa.

\subsection{Análise Multidimensional Aditiva do Corpus of English Lyrics: perfil do registro letra de música}

O arcabouço teórico-metodológico desta pesquisa é a Linguística de Corpus, uma área dos estudos linguísticos que se propõe ao estudo da língua em uso e, de acordo com Berber Sardinha:

se ocupa da coleta e exploração de corpora, ou conjuntos de dados linguísticos textuais, em formato legível por computador, que foram coletados criteriosamente com o propósito de servirem para a pesquisa de uma língua ou de uma variedade linguística (BERBER SARDINHA, 2004, p. 3).

Um corpus pode ser definido como uma "coleção grande de textos naturais (escritos ou falados) que podem ser armazenados eletronicamente" (REPPEN, 2010, p. 2). Estudos na área de LC são baseados em análise empírica de textos autênticos (em outras palavras, o corpus), a partir do uso de programas computacionais, incorporando análise quantitativa e qualitativa, por meio de interpretações funcionais (CONRAD, 2011). Dentro da LC existe uma abordagem para análise de corpora que emprega uma série de procedimentos estatísticos multivariados (principalmente análise fatorial) para 
determinar parâmetros de coocorrência entre características linguísticas (BIBER, 1988), denominada Análise Multidimensional (AMD).

Há essencialmente dois tipos de AMD, a de cunho funcional e a de cunho lexical. Na presente pesquisa trabalhamos apenas com a AMD de cunho funcional, que foi inaugurada por Biber (1988) em um estudo sobre os registros falados e escritos em inglês, a partir da análise de 67 variáveis linguísticas presentes em um corpus composto por 481 textos que representam 23 diferentes registros da língua inglesa, tais como biografias, cartas pessoais, conversas face a face, prosa acadêmica, discursos planejados, entre outros. Esse estudo culminou na identificação de cinco dimensões principais de variação de registros da língua inglesa. O Quadro 2, a seguir, apresenta as dimensões funcionais identificadas por Biber (1988):

Quadro 2 - Dimensões de variação da língua inglesa

\begin{tabular}{c|l}
\hline Dimensão 1 & Produção com Interação versus Informacional \\
\hline Dimensão 2 & Preocupações Narrativas versus Não Narrativas \\
\hline Dimensão 3 & Expressões Explícitas versus Dependentes do \\
& Contexto \\
\hline Dimensão 4 & Persuasão Explícita \\
\hline Dimensão 5 & Informação Abstrata versus Não Abstrata \\
\hline
\end{tabular}

Fonte: Delfino (2019), para esta pesquisa, adaptado de Biber (1988)

Essas dimensões possuem uma base linguística formada por características correlacionadas, ou seja, que ocorrem simultaneamente nos textos. Nesse sentido, a 
dimensão "Produção com Interação versus Informacional" é formada por dois blocos de características linguísticas correlacionadas que atuam em torno de duas funções distintas: de um lado, proporcionar as condições para a interação e do outro, para proporcionar as condições para a produção de informação: o polo envolvido, típico de registros que são formados por conversas, cartas pessoais e discursos, é composto por pronomes de primeira e segunda pessoa ( $I$, you), verbos no presente e contrações (don't, can't), entre outros; e o polo informacional, típico de registros como documentos oficiais, reportagem jornalística e biografias é composto por substantivos, preposições e adjetivos atributivos.

Cada texto da língua inglesa possui algum tipo de informação ou de interação. A AMD permite mensurar a quantidade de informação e de interação de cada texto por meio da presença das características linguísticas associadas a cada lado (ou polo) da dimensão. Quando se calcula a média de interação e de informação de cada registro (isto é, dos textos que pertencem a um determinado registro) nessa dimensão, podese saber qual a propensão de um determinado registro em relação à dualidade interação/informação. Assim, podemos estabelecer se um determinado registro é mais informativo ou mais interativo, em relação aos demais. De fato, Biber (1988) mostra que a conversação informal, face a face, é muito interativa, na medida em que sua função precípua é permitir que os participantes interajam entre si; essa interação, por sua vez, está ancorada, na língua inglesa, no uso constante de características linguísticas como as mencionadas acima.

É importante frisar que não é cada característica linguística individual que tem a função de permitir a interação, mas sim várias dessas características atuando em 
conjunto. Ou seja, pronomes de primeira e segunda pessoas servem para diversas funções comunicativas, mas quando se associam a outras características como verbos no tempo presente e contrações, por exemplo, geralmente o fazem quando existe a necessidade de interação face a face em contextos informais entre os usuários. Os textos individuais do registro conversação cara a cara geralmente possuem tipicamente escores altos no polo da interação dessa dimensão. Já os textos que fazem pouco uso dessas características associadas à interação e, ao mesmo tempo, empregam frequentemente características linguísticas como substantivos, preposições e advérbios, o fazem devido à necessidade de veicular informação de forma intensa, como textos de enciclopédia e artigos acadêmicos.

O mesmo acontece com as demais dimensões identificadas, listadas no Quadro 2. Outra característica importante da AMD é a de que todo texto é entrecortado por todas as dimensões de variação. Daí a nomenclatura "multidimensional", pois não é somente a língua ou registro que possui diversas dimensões, mas sim cada um dos textos. Desse modo, uma conversação informal face a face, qualquer uma, é marcada, de algum modo, por todas as cinco dimensões. Ela é, sempre, de algum modo, informal ou informacional (dim. 1), mais narrativa ou menos narrativa (dim. 2), e assim por diante.

Há diversas pesquisas AMD de cunho funcional, como a do espanhol (BIBER; TRACY-VENTURA, 2007), a do português brasileiro (BERBER SARDINHA; KAUFMANN; ACUNZO, 2014), televisão (VEIRANO PINTO, 2014), música pop (BÉRTOLI-DUTRA, 2010) e texto jornalístico (KAUFFMANN, 2005). 
Como pode-se perceber, a identificação da coocorrência das características linguísticas nos textos é fundamental para a identificação das dimensões. Sem ela, não é possível saber a incidência dos grupos de características linguísticas, sem o qual não é possível detectar os padrões de coocorrência que darão vazão à identificação das dimensões de variação.

O primeiro passo da análise do corpus CoEL para a classificação da análise multidimensional foi o procedimento de etiquetagem por meio do programa computacional Biber Tagger; na sequência, fez-se a checagem manual do corpus CoEL para, se necessário, corrigir problemas de interpretação de grafia das palavras pelo programa. O terceiro passo foi o cálculo automático dos valores das variáveis com o auxílio do programa computacional Biber Tag Count, que já está programado para normalizar os valores absolutos obtidos por $1.000^{\mathrm{ii}}$, com vistas a eliminar vieses causados pela diferença entre os tamanhos dos textos, bem como para padronizar os valores das variáveis normalizadas do corpus.

Com os resultados fornecidos por essa análise, a comparação do CoEL com a variação linguística da língua inglesa foi realizada. Foi possível, assim, alocar o corpus inteiro e os seus subgrupos, representados pelas bandas ou pelo músico, nas cinco dimensões propostas por Biber em 1988.

\subsection{Elaboração dos exercícios}

A partir dos dados obtidos, tanto na análise dos padrões como na AMD, passamos à fase de elaboração dos exercícios. Todas as aulas seguiram o plano de 
aula, detalhado no Quadro 3 abaixo, que contou com exercícios baseados em corpus (itens $\mathrm{E}$ e $\mathrm{F}$ abaixo) e exercícios que não foram baseados em corpus (itens $\mathrm{A}$ a $\mathrm{D}$ e $\mathrm{G}$ a J abaixo), mas que foram importantes para a montagem da aula. Todas as aulas continham exercícios que contemplavam:

Quadro 3 - Plano de aula

\begin{tabular}{|l|}
\hline (A) Warm-up (aquecimento para o início da aula) e Listening (escuta); \\
\hline (B) Cognatos; \\
\hline (C) Background (histórico) da música; \\
\hline (D) Compreensão do texto; \\
(E) Foco na léxico-gramática: concordâncias; gráficos do COCA; bundles \\
palavras-chave; variação de registro; \\
\hline (F) Uso de ferramentas: AntConc (concordâncias e Key Words) \\
\hline (G) Análise de frases; \\
\hline (H) Nuvem de palavras; \\
\hline (I) Jogos;
\end{tabular}

Fonte: Delfino (2016) para esta pesquisa.

A partir da literatura baseada em exercícios com corpora (ACUNZO, 2012; ACUNZO et al. 2014; BERBER SARDINHA et al., 2011) e no uso de letras de música para o ensino de inglês (MURPHEY, 1990; BERTÓLI-DUTRA, 2002; DOMONEY; HARRIS, 
1993), a pesquisadora delimitou os tipos de exercícios a serem utilizados nas atividades, expressos no Quadro 4 a seguir.

Quadro 4-Tipos de exercícios: taxonomia

(1) Blank filling: preencher os espaços em branco conforme ouve a música

(2) Singing: cantar a música

(3) Concordance analysis: análise de linhas de concordância

(4) Awareness raising: o aluno, através do exercício, passa a perceber a língua estudada

(5) Pattern analysis: análise de padrões

(6) Chart analysis: análise de gráficos

(7) Register analysis: análise de registros

(8) Reading comprehension: compreensão de leitura

(9) Listening comprehension: compreensão auditiva

(10) Writing practice: elaboração de frases

(11) Word clouds analysis: nuvem de palavras

Fonte: Delfino (2016) para esta pesquisa.

Os exercícios que envolvem cantar a música e compreensão de leitura e auditiva não são baseados em corpus, mas foram importantes para a elaboração da aula. Já os demais tipos dependem do ambiente baseado em corpus desenvolvido para que se pudesse entender como ocorre o processo de aprendizagem de inglês como língua estrangeira a partir de letras de música. Para se chegar a essas conclusões, a 
pesquisadora realizou entrevistas com os alunos para descobrir a opinião deles em relação ao processo de aprender inglês utilizando letras de música e Linguística de Corpus.

\subsection{Entrevistas}

A professora/pesquisadora entrevistou três alunos que participaram do curso durante os três semestres para saber a opinião deles sobre o processo de trabalhar com LC e aprendizado de inglês. Essas entrevistas foram gravadas e utilizadas para a reflexão da professora/pesquisadora, tanto na montagem dos exercícios como na descoberta do que é relevante para o aluno. Os entrevistados foram indagados também a respeito da metodologia nova, pois os alunos, em geral, não são consultados sobre os métodos de ensino, embora, como princípio, seja importante que o aluno se sinta parte integrante de seu processo de aprendizagem. No quadro 5, abaixo, encontram-se as perguntas que os alunos responderam.

\section{Quadro 5 - Entrevista}
(1) Como você costuma estudar inglês?
(2) Você usa o dicionário?
(3) Você usa gramática para estudar inglês?
(4) Como e para que você usa o computador?
(5) Como você vê a música no aprendizado da língua inglesa? 
(6) Você acha que os programas COCA e Ant Conc ajudam no aprendizado ou atrapalham? Como você compara esses programas com o livro didático?

(7) Em casa você chega a usar o COCA e o Ant Conc?

(8) Você acha que os handouts ajudam? E os exercícios?

\section{Resultados}

Estes relatos são descritos a partir do resultado de uma colocação cuja palavra nódulo está presente entre as 100 mais frequentes tanto no corpus de estudo quanto no de comparação. A referida colocação foi escolhida por ter sido usada em sala de aula e na confecção de exercícios com Linguística de Corpus e música. Tal colocação é formada a partir do item lexical like que, no CoEL, é a 29a palavra mais frequente, e, no COCA, a 58a mais frequente. Após a comparação de 100 linhas de concordância em ambos os corpora, pode-se dizer que os padrões like + pronome, assim como pronome + like, são muito comuns em ambos os corpora, estando presente em $46,84 \%$ das letras de música do CoEL e em $87,85 \%$ dos textos do COCA e as seguintes combinações são as mais frequentes:

Tabela 2 - Colocados de like e suas frequências no corpus CoEL

\begin{tabular}{|c|c|}
\hline Item & $\begin{array}{c}\text { Frequência no corpus } \\
\text { CoEL }\end{array}$ \\
\hline Like I & $92(10,5 \%)$ \\
\hline
\end{tabular}




\begin{tabular}{|c|c|}
\hline $\begin{array}{c}\text { Like you } \\
\text { I like }\end{array}$ & $88(10,2 \%)$ \\
Like it & $63(7,5 \%)$ \\
Like me & $41(4,5 \%)$ \\
Like we & $22(2,5 \%)$ \\
\end{tabular}

Fonte: Delfino (2016)

$\mathrm{Na}$ sequência, na tabela abaixo encontram-se algumas das palavras mais frequentes no corpus de estudo e suas posições no corpus de comparação, além da quantidade de textos que as contêm. Com cada uma das palavras presentes na Tabela 3, linhas de concordância foram rodadas e utilizadas em exercícios aplicados na sala de aula. Nem todas as palavras mais frequentes foram utilizadas porque a autora escolheu as palavras de conteúdo, ou seja, preposições, verbos, advérbios e substantivos dentre as mais frequentes.

Tabela 3 - Palavras de conteúdo mais frequentes nos corpora de estudo e de comparação utilizadas nas aulas

\begin{tabular}{|l|c|c|c|}
\hline Palavra & Ranking & $\begin{array}{c}\text { Presença em Número de } \\
\text { no CoEL }\end{array}$ & $\begin{array}{c}\text { Ranking no } \\
\text { Textos (Letras de } \\
\text { Música) } / \%\end{array}$ \\
\hline To & 04 & $540 / 92,31$ & 04 \\
\hline In & 10 & $445 / 76,07$ & 07 \\
\hline That & 11 & $413 / 70,60$ & 08 \\
\hline
\end{tabular}


DOI: $10.12957 /$ palimpsesto.2019.45569

\begin{tabular}{|l|c|c|c|}
\hline On & 12 & $377 / 64,44$ & 17 \\
\hline Your & 13 & $349 / 59,66$ & 69 \\
\hline Of & 15 & $377 / 64,44$ & 03 \\
\hline Be & 16 & $334 / 57,09$ & 23 \\
\hline But & 18 & $355 / 60,68$ & 26 \\
\hline For & 19 & $319 / 54,53$ & 13 \\
\hline Know & 20 & $343 / 58,63$ & 74 \\
\hline So & 21 & $325 / 55,56$ & 48 \\
\hline Just & 23 & $315 / 53,85$ & 63 \\
\hline Like & 24 & $274 / 46,84$ & 58 \\
\hline Get & 28 & $246 / 42,05$ & 52 \\
\hline If & 29 & $249 / 42,56$ & 53 \\
\hline Can & & $245 / 41,88$ & \\
\hline
\end{tabular}

Fonte: Delfino (2016)

A partir dos resultados encontrados na Análise Multidimensional, foi possível posicionar os textos do CoEL nas dimensões do inglês geral obtidas por Biber (1988), chegando aos seguintes dados ilustrados no Gráfico 2, abaixo: 
Gráfico 2 - Corpus CoEL ao longo das 05 dimensões de Biber (1988)

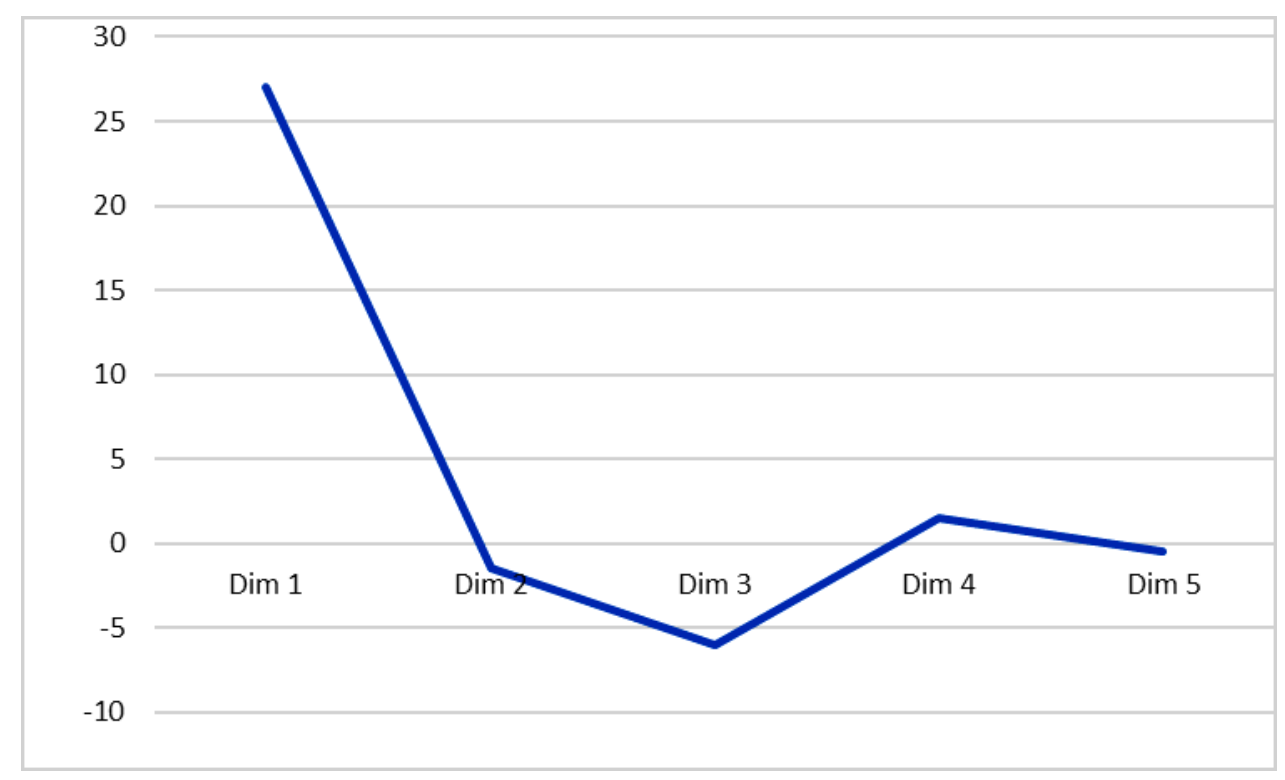

Fonte: Delfino (2016)

A partir do Gráfico 2 acima, pode-se dizer que as músicas são interativas (Dimensão 1 - Produção com interação versus Produção informacional), não possuem marca de narratividade (Dimensão 2 - Discursos Narrativos versus não Narrativos), são dependentes do contexto (Dimensão 3 - Referências Elaboradas versus Dependentes do Contexto), argumentativas (Dimensão 4 - Argumentação Explícita) e não abstratas (Dimensão 5 - Estilo Abstrata versus Estilo não Abstrato).

\subsection{Desenvolvimento dos exercícios}

Conforme observa-se no Quadro 4 (Taxonomia de Exercícios), os exercícios se enquadraram em 11 tipos e foram desenvolvidos com ferramentas e recursos variados, a fim de que o professor possa prepará-los previamente, se os recursos 
computacionais não estiverem disponíveis em sala de aula. Dessa perspectiva, vê-se abaixo linhas de concordância previamente selecionadas pela professora, que as levou impressas para a sala de aula, ao invés de usar o site COCA durante a aula. Esse tipo de exercício parece despertar no aluno além da consciência da língua, também sua autonomia sobre o aprendizado, conforme relato de alunos ("As linhas de concordância ajudam, porque você aprende o que vem antes e depois e porque para mim, que sou muito ruim de inglês, começo a aprender alguma coisa" - Aluno 02 entrevistado).

Vimos nas músicas que tired of foi seguido de Ving (Verbo no Ing), mas ele nem sempre aparece seguido de verbo. Vamos encontrar outros padrões para essa expressão no COCA?

\begin{tabular}{|c|c|}
\hline$\underline{1}$ & Carlotta apparently was tired of bandying words. \\
\hline$\underline{2}$ & $\underline{\text { I was already so tired of the fight we were about to have. }}$ \\
\hline$\underline{3}$ & $\underline{\text { She gets tired of all us men. }}$ \\
\hline$\underline{4}$ & $\begin{array}{l}\text { Once we got tired of pulling her back into her seat. } \\
\underline{5}\end{array}$ \\
\hline$\underline{6}$ & $\begin{array}{l}\text { He was getting tired of being on the road all the time. } \\
\text { She was getting tired of being treated like a victim. }\end{array}$ \\
\hline$\underline{7}$ & $\underline{\text { When he got tired of being any other place. }}$ \\
\hline
\end{tabular}




\begin{tabular}{|l|c|}
\hline$\underline{8}$ & Jade never tired of him. \\
\hline$\underline{9}$ & $\underline{\text { Dom was tired of them. }}$ \\
\hline$\underline{10}$ & She is tired of people looking at her like that. \\
\hline$\underline{11}$ & We never got tired of seeing. \\
\hline$\underline{12}$ & She was just so tired of always hiding part of herself. \\
\hline
\end{tabular}

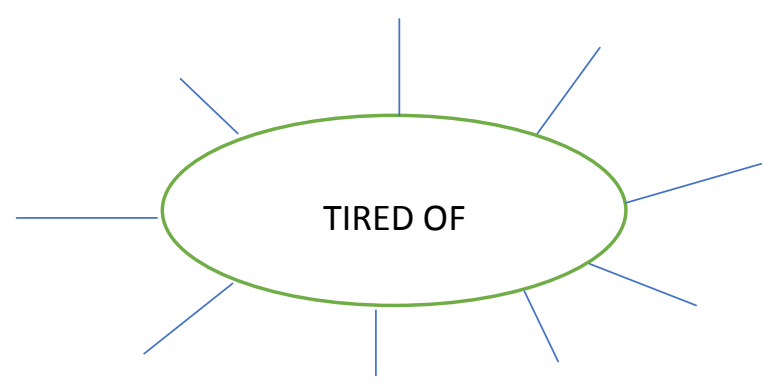

Por questões de espaço, exemplifica-se, aqui, apenas mais um exercício (exemplo de uma aula completa encontra-se no Apêndice), a partir de resultados obtidos na Análise Multidimensional, que pode levar os alunos a uma melhor compreensão sobre os diferentes registros e saber que mesmo conseguindo "encaixar" a palavra num texto por sua tradução estar correta, ela pode não ser a mais adequada para aquele contexto social (Aluno 3).

As linhas de concordância abaixo foram retiradas de diferentes registros.

Classifique-as em Orais (0), se elas apresentarem similaridade com uma conversa, ou Letrados (L), se a similaridade for com um texto informativo: 


\begin{tabular}{|c|c|}
\hline ( ) & \\
\hline 1 & $\begin{array}{l}\text { He told a news conference, amid complaints of being trampled by } \\
\text { German boots. }\end{array}$ \\
\hline 2 & Any other complaints against him? \\
\hline 3 & $\begin{array}{l}\text { He's the first U.S. church official to be charged over the handling of } \\
\text { abuse complaints. }\end{array}$ \\
\hline 4 & The reporters found the court records of domestic violence complaints. \\
\hline 5 & I'm not hearing any complaints. \\
\hline ( ) & \\
\hline 1 & $\begin{array}{l}\text { How could Dominic reassure him that his villainy was one of the most } \\
\text { common complaints he heard? }\end{array}$ \\
\hline 2 & $\begin{array}{l}\text { He really was excellent, despite his unorthodox methods and the litany } \\
\text { of complaints from those who tried to supervise him. }\end{array}$ \\
\hline 3 & $\begin{array}{l}\text { Tiny candleflames that dotted the brush with fire from his attack } \\
\text { crackled their complaints before expiring into steams. }\end{array}$ \\
\hline 4 & $\begin{array}{l}\text { Congress and President Pierce are getting too many complaints from } \\
\text { voters in the Lone Star State. }\end{array}$ \\
\hline
\end{tabular}




\begin{tabular}{|c|c|}
\hline 5 & Complaints should be submitted in writing directly to Ubernanny, Inc. \\
\hline ( ) & \\
\hline 1 & $\begin{array}{l}\text { So it is tempting for progressives to dismiss complaints about } \\
\text { redistribution of wealth as ignorant or hypocritical. }\end{array}$ \\
\hline 2 & $\begin{array}{l}\text { Arpaio's officers were forced to hand in their federal credential due to } \\
\text { complaints about their immigration enforcement tactics. }\end{array}$ \\
\hline 3 & The stations were inundated by complaints from viewers. \\
\hline 4 & $\begin{array}{l}\text { The Consumer Product Safety Comission's Web site is loaded with } \\
\text { complaints about injuries from toning shoes. }\end{array}$ \\
\hline 5 & $\begin{array}{l}\text { But the diocese did not consult the review board about the complaints } \\
\text { involving Ratigan, says Caccamo. }\end{array}$ \\
\hline ( ) & \\
\hline 1 & "I am not sure their complaints are valid", he said. \\
\hline 2 & At the firing range, the complaints flew thick and fast. \\
\hline 3 & There seems to be a continual group of people e-mailing complaints all \\
\hline
\end{tabular}




\begin{tabular}{|c|c|}
\hline & the time. \\
\hline 4 & $\begin{array}{l}\text { The company paid an additional } \$ 1.2 \text { million and settled related } \\
\text { regulatory complaints that it had maintained false books and records. }\end{array}$ \\
\hline 5 & $\begin{array}{l}\text { Both candidates claim records for addressing the district's perennial } \\
\text { complaints: rundown housing, ineffective schools and wide } \\
\text { unemployment. }\end{array}$ \\
\hline ( ) & \\
\hline 1 & A woman of 38 complaints of dysmenorrhea and dyspareunia. \\
\hline 2 & $\begin{array}{l}\text { Past serious illness and hospitalization, unintentional weight loss, and } \\
\text { self-reported memory complaints. }\end{array}$ \\
\hline 3 & $\begin{array}{l}\text { The library has not received complaints from users about lost access to } \\
\text { print titles that that were withdrawn. }\end{array}$ \\
\hline 4 & $\begin{array}{l}\text { The URI Library did not receive any complaints after the withdrawal of } \\
\text { print volumes. }\end{array}$ \\
\hline 5 & $\begin{array}{l}\text { Fatigue, insomnia, memory loss and joint muscle pain were frequent } \\
\text { complaints among those with a positive PCR result for B. koehlarae. }\end{array}$ \\
\hline
\end{tabular}

O tempo de execução dos exercícios varia de acordo com a disponibilidade de 
um computador em sala de aula ou não, com o número de alunos e seu rendimento, entre outros fatores. Podemos dizer que, quando o professor leva as linhas de concordância impressas para a sala de aula, o rendimento dos alunos parece ser melhor, por ficarem mais focados no que está sendo apresentado. Quando os alunos estão no computador, a chance de dispersão pode ser maior, pois alguns podem acessar outros sites que não fazem parte da aula.

Cabe ressaltar que todos os exercícios podem ser utilizados em aulas individuais ou em grupos. Os exercícios aqui presentes foram formulados e testados num grupo de alunos, porém no caso de aulas individuais, os estudantes podem discutir as questões juntamente com o professor, que terá um papel de participante da discussão.

\subsubsection{Entrevistas}

Três alunos, que participaram dos três semestres do curso, foram entrevistados e deram sua opinião em relação ao processo de aprendizagem por música, sob os preceitos da LC. No Quadro 6, a seguir, trechos significativos das entrevistas em relação ao uso de corpora são reproduzidos. Pode-se dizer que os alunos parecem dizer que o estudo de inglês por essa metodologia os ajuda a identificar diferenças entre os registros, porém alguns ainda se sentem inseguros para utilizar os programas relacionados à $\mathrm{LC}$ em casa, sem o auxílio da professora, com exceção do Aluno 3, que até coletou e montou seu próprio corpus de músicas favoritas e fez pesquisas em casa, com o auxílio do programa AntConc. 
Em suma, os relatos sugerem que os alunos ainda estariam presos a dicionários e tradutores on-line. A diferença agora é que adequam o significado da palavra nova ao contexto estudado. O aluno 2 parece demonstrar uma mudança no seu próprio aprendizado, visto que, antes do curso, relata que quando aprendia uma palavra nova, lia e repetia a palavra várias vezes e agora já lê a frase inteira para entender. O mais interessante é que esse comportamento também se repete no curso de inglês regular e não apenas com a música - ou seja, ele parece estar pesquisando a língua mesmo quando a professora não está presente. Os alunos também relatam que os exercícios presentes nos handouts ajudam a fixar o que eles aprendem e servem para que os aprendizes possuam um parâmetro do que estão aprendendo no curso.

O curso parece ter estimulado os alunos a pesquisarem sites e programas de televisão envolvendo ensino e música, tais como Inglês com Música, da TV Cultura. Além disso, seus relatos parecem mostrar que eles gostam de trabalhar com os programas computacionais aliados à música, que é uma maneira diferente e mais divertida de se trabalhar do que com o livro didático.

\section{Quadro 6: Trechos de entrevista}

Aluno 1:

A música ajuda nas expressões coloquiais, porque eles cantam como falam, como o in com o apóstrofo como o believin' de hoje.

O uso de corpora é bom, porque te mostra de uma forma clara as diferenças entre 


\begin{abstract}
textos. Se eu fosse olhar sozinha, eu teria mais dificuldades, como você mostra, eu consigo enxergar melhor. Sozinha eu não consigo, mas o gráfico (do COCA) é bem claro.

Talvez agora com o uso do COCA eu tenha mais facilidade de pesquisar em inglês no futuro, mas agora não.

Eu uso muito o dicionário para confirmar se o que eu identifiquei era aquilo mesmo.
\end{abstract}

Aluno 2:

Eu costumava ler a palavra e ficava repetindo para memorizar; agora, depois das aulas de música eu leio toda a frase e tento pegar tudo o que eu vou entendendo e vou estudando assim, até para prova do curso regular.

Eu uso o computador em casa para entrar no COCA e no Ant Conc e eles ajudam bastante. Eu vou observando outras palavras que eu quero conhecer e vejo o que vem antes e vem depois e ajuda bastante.

Eu estou adorando o curso, tudo o que tem música me atrai. Por exemplo, eu nunca tinha visto o programa Inglês com Música da Cultura e, agora, depois do seu curso me identifiquei e não perco um.

Eu guardo todos os handouts que você dá, porque no final quero ver como foi indo o curso desde a primeira aula e eu também como fui. Quero mostrar para algumas pessoas, porque quero ensinar para algumas pessoas o que eu aprendi.

As linhas de concordância ajudam, porque você aprende o que vem antes e depois e 
porque para mim, que sou muito ruim de inglês, começo a aprender alguma coisa.

Antes, quando assistia a uma entrevista, só prestava atenção na tradução, hoje, depois do curso, presto atenção por que a pessoa usou aquelas palavras.

Aluno 3:

Eu sempre convivi com inglês em música e jogo, pesquisando alguma frase no Google e agora uso o computador para estudar. O tradutor me dá vários significados e aí eu adequo qual é o correto para o que eu estou vendo.

Eu gosto muito de música, ouço o dia inteiro e dá curiosidade de saber o que está falando, então eu vou sempre na letra.

É bom ir ao AntConc para aprender coisas novas como that no meio da frase, eu não sabia que ele tinha o sentido de que com esse programa fica mais fácil de aprender. No COCA, os gráficos mostram onde é mais usado, no falado ou escrito. Já as linhas de concordância mostram detalhes que as pessoas não atentam normalmente, lendo a frase e chegando ao que deve ser o significado mais provável.

No AntConc, o que é legal é poder colocar todas as letras de música lá e estudar as palavras que estão no meio das letras de músicas que eu gosto, é incrível. É uma maneira diferente, mais divertida de estar aprendendo, de estar observando coisas que não se vê normalmente em livros.

Os handouts são bons para acompanhar, porque às vezes aprendemos uma coisa nova, mas só fixamos com os exercícios que você traz. 
Em casa eu salvo as letras de música que eu gosto e vou jogando no AntConc e vendo que os padrões se repetem em diferentes músicas e as palavras mais frequentes também são as mesmas, acho que porque o registro é o mesmo, né professora?

Fonte: Delfino (2016)

\section{Considerações finais}

Podemos dizer que quando os alunos se habituam a trabalhar com exercícios com corpus, o resultado pode ser muito satisfatório, haja vista que a professora consegue refletir melhor sobre abordagens específicas a serem utilizadas de forma bemsucedida com cada grupo, além de apontar o que precisa ser adaptado ou eliminado de uma futura aula. A partir do diário, também foi possível adaptar os exercícios de linhas de concordância. Ao invés de se trabalhar direto no corpus, as linhas de concordância foram impressas para que a professora não ficasse na dependência da internet.

Em relação à análise lexicogramatical, pode-se dizer que as palavras mais frequentes nas letras das músicas usam padrões comuns encontrados nos registros orais da língua inglesa, tais como pronome + like (I like) e like + pronome (like you), get + preposição (get to), go + preposição ( $g o$ to). Em função disso, pode-se concluir que é possível utilizar músicas para ensinar padrões do inglês oralizado.

A partir da Análise Multidimensional, pode-se dizer que as músicas possuem um perfil multidimensional distinto: envolvido (Dimensão 1), não narrativo (Dimensão 2), dependente do contexto (Dimensão 3), argumentativo (Dimensão 4) e não abstrato (Dimensão 5). Também é importante ressaltar que as músicas podem ser utilizadas para 
ensinar as características linguísticas associadas com esse perfil multidimensional, além de associar o ensino de tais características, que não são comuns no perfil descrito acima, com textos que envolvam músicas e, assim, conseguir abranger uma gama mais ampla do ensino de inglês como LE por meio da LC com letras de música e textos que fazem parte do universo do aluno, até para que eles se conscientizem de que diferentes registros possuem diferentes características linguísticas associadas.

Com base em Bertóli-Dutra (2010), queremos buscar caminhos ao colocarmos a música próxima ao registro conversacional, devido, principalmente, a grande presença de pronomes de primeira e segunda pessoa $(I$, you $)$, verbos no presente e contrações características linguísticas bem marcantes de um diálogo.

Em relação à taxonomia, é necessário, pois, analisar que quando o pesquisador possui uma gama de tipos de exercícios que ele pode elaborar, a atividade segue um padrão, tornando mais fácil a adaptação dos exercícios com outras músicas e/ou textos.

As entrevistas mostraram a opinião dos alunos em relação ao aprendizado com corpus, segundo a qual eles estariam estimulados a fazer pesquisa linguística com os programas aprendidos dentro e fora da sala de aula. Os alunos também parecem indicar ser mais motivador aprender inglês por meio da nova metodologia do que a partir do livro didático.

A pesquisa pôde proporcionar aos aprendizes de aulas de LE a oportunidade de aliar prazer e responsabilidade por seu aprendizado, na medida em que os discentes aprenderam a utilizar as ferramentas da LC e realizaram pesquisas quanto aos aspectos linguísticos que encontravam em outros textos com auxílio dos software ${ }^{i i i}$ utilizados em sala de aula. Isso tornou as aulas mais significativas e estimulantes, até para a pesquisa fora da sala de aula. 


\section{Referências}

ACUNZO, C. M. Uso de corpora para o ensino da língua inglesa para profissionais de publicidade. 151f. São Paulo. Dissertação (Mestrado em Linguística Aplicada e Estudos da Linguagem). LAEL, PUC/SP, 2012.

ACUNZO, C. M.; DELEGÁ-LUCIO, D.; VEIRANO PINTO, M.; SOUZA, R. C. What's on: aprenda inglês com filmes e séries. São Paulo: Senac; Martins Fontes, 2014.

ANTHONY, L. Laurence Anthony's Website. Disponível em: <http://www.laurenceanthony.net/software.html>. Acesso em: 5 jan. 2014.

BERBER SARDINHA, T. Análise Multidimensional. D.E.L.T.A., n. 16, v. 1, 2000 (a), p. 99 127.

BERBER SARDINHA, T. Linguística de Corpus: histórico e problemática. D.E.L.T.A. vol. 16, n. 2, 2000 (b).

BERBER SARDINHA, T. Linguística de Corpus. São Paulo: Manole, 2004.

BERBER SARDINHA, T. Como usar a Linguística de Corpus no ensino de língua estrangeira. Por uma Linguística de Corpus educacional brasileira. In: VIANA, V.; TAGNIN, S. E. O. (orgs.). Corpora no ensino de línguas estrangeiras: Como usar a Linguística de Corpus no ensino de língua estrangeira: por uma Linguística de Corpus educacional brasileira. São Paulo: Hub Editorial, 2010, p. 301-56.

BERBER SARDINHA, T.; SHEPHERD, T. M. G.; DELEGÁ-LÚCIO, D.; FERREIRA, T. L. S. B. (orgs.). Tecnologias e mídias no ensino de inglês: o corpus nas "receitas". São Paulo: Macmillan, 2011.

BERBER SARDINHA, T.; KAUFMANN, C.; ACUNZO, C. M. A multidimensional analysis of register variation in Brazilian Portuguese. Corpora, v. 9, n. 2, 2014, p. 239-271.

BERTÓLI-DUTRA, P. Explorando a Linguística de Corpus e letras de música na produção de atividades pedagógicas. São Paulo. Dissertação (Mestrado em Linguística Aplicada e Estudos da Linguagem). LAEL, PUC/SP, 2002.

BERTÓLI-DUTRA, P. Linguagem da música popular anglo-americana de 1940 a 2009. 286f. São Paulo. Tese (Doutorado em Linguística Aplicada e Estudos da Linguagem). LAEL, PUC/SP, 2010. 
BIBER, D. Variation across speech and writing. Cambridge: Cambridge University Press, 1988.

BIBER, D.; TRACY-VENTURA, N. Dimensions of register variation in Spanish. In: PARODI, G. (org.). Working with Spanish Corpora. London: Continuum, 2007, p. 54-89.

CONRAD, S. Variation in corpora and its pedagogical implications. In: VIANA, V.; ZYNGIER, S.; BARNBROOK, G. (eds.). Perspectives on Corpus Linguistics. Philadelphia: John Benjamins, 2011, p. 47-62.

DAVIES, M. Corpus of contemporary American English. Disponível em: $<$ http://corpus.byu.edu/>. Acesso em: 5 jan. 2016.

DELFINO, M. C. N. O uso de música para ensinar inglês em um ambiente baseado em corpus. 2016, 136f. Dissertação (Mestrado em Linguística Aplicada e Estudos da Linguagem) - LAEL. PUC-SP. São Paulo, 2016.

DOMONEY, L.; HARRIS, S. Justified and ancient: pop music in EFL classrooms. ELT Journal, v. 47, 1993, p. 234-41.

HOEY, M. A world beyond collocation: new perspectives on vocabulary teaching. In: LEWIS, M. (org.). Teaching collocation: further developments in the lexical approach. Hove: LTP, 2000, p. 224-243.

KAUFFMANN, C. O corpus do jornal: variação linguística, gêneros e dimensões da imprensa diária escrita. 2005, 202f. Dissertação (Mestrado em Linguística Aplicada e Estudos da Linguagem) - LAEL, PUCSP, São Paulo, 2005.

LITTLE, J. Pop and rock music in the ESL classroom. TESL Talk, 14, 1983, p. 40-4.

MURPHEY, T. Music and song. Oxford: Oxford University Press, 1990, 151p.

REPPEN, R. Using corpora in the language classroom. Cambridge University Press, 2010.

VEIRANO PINTO, M. A linguagem dos filmes norte-americanos ao longo dos anos: uma abordagem multidimensional. 2014, 488f. Tese (Doutorado em Linguística Aplicada e Estudos da Linguagem) - PUC-SP, São Paulo, 2014. 


\section{APÊNDICE}

\section{Exemplo de uma aula completa}

Exercício 1: Leia o título da música. Qual deve ser o tema da aula de hoje?

\section{She will be loved - Maroon 5}

Beauty queen of only eighteen she Had some trouble with herself

He was always there to help her, she Always belonged to someone else

I drove for miles and miles and wound up At your door

I've had you so many times but somehow I want more

I don't mind spendin' everyday

Out on your corner in the pourin' rain Look for the girl with the broken smile Ask her if she wants to stay awhile

And she will be loved, and she will be loved

Tap on my window, knock on my door, I Want to make you feel beautiful

I know I tend to get so insecure It doesn't matter anymore

It's not always rainbows and butterflies
It's compromise that moves us along yeah My heart is full, and my door's always open You can come anytime you want yeah

I don't mind spendin' everyday

Out on your corner in the pourin' rain Look for the girl with the broken smile Ask her if she wants to stay awhile

And she will be loved, and she will be loved And she will be loved, and she will beloved

I know where you hide alone in your car Know all of the things that make you who you are

I know that goodbye means nothing at all Comes back and makes me catch her every time she

Falls

Yeah, tap on my window, knock on my door, I Want to make you feel beautiful 
DOI: $10.12957 /$ palimpsesto.2019.45569

I don't mind spendin' everyday

Out on your corner in the pourin' rain oh Look for the girl with the broken smile Ask her if she wants to stay awhile

And she will be loved, and she will be loved And she will be loved, and she will beloved
Please don't try so hard to say good-bye I don't mind spendin' everyday, out on your corner in the pourin' rain Please don't try so hard to say good-bye

Exercício 2: Selecione agora 05 palavras na letra da música que sejam parecidas com palavras em português. Vamos também checar no dicionário online? Elas possuem o significado que você imaginava?

Exercício 3: Vamos ao site http://en.wikipedia.org/wiki/She_Will_Be_Loved eresponda: Quando a música foi lançada?

Quem é (são) seu(s) compositor(es)?

Essa música atingiu o número 1 das mais tocadas? Onde?

Algum cantor / banda regravou essa música? Quem? Qual versão é a melhor? Vamos ouvir?

Exercício 4: Agora volte na letra da música, encontre e destaque TO e FOR.

Exercício 5: Leia a música e responda: What's the song about?

Exercício 6: Answer True (T) or False (F) to the sentences according to the song:

1 ( ) The woman is old.

2 () She always helped him.

3 ( ) He always helped her.

4 ( ) He likes to be in the rain.

5 ( ) Life is always made of happiness. 
6 () She is always welcome to his place.

7 ( ) He doesn't want her in his place.

8 ( ) She wants to say goodbye to him.

Exercício 7: Nesta música vimos alguns significados da palavra TO. Qual significado será o mais comum? Uma das grandes maneiras de aprender inglês é saber encontrar as respostas sozinho. Uma maneira de encontrar as respostas sozinho é pesquisar no corpus. Então, vamos verificar essa informação? Vamos olhar essas linhas de concordâncias, retiradas do COCA e aproveitar também para descobrir quais os padrões que aparecem. Ou seja, quais palavras acompanham mais frequentemente o TO em cada um dos significados. Veja com seu amigo os padrões que ele encontrou. São parecidos ou diferentes dos seus? Em que sentido?

1 Much of that growth can be traced to the success of ACM's international initiatives.

2 It was also a year that marked great strides in ACM's commitment to improve the

3 In promoting the importance of computer science education to a mass audience.

4 In India encouraging women from the region to explore the limitless opportunities of a

5 Teachers Association issued a landmark report on the vital need for the U.S. to create a strong k-12 comnuter

6 And the Dot Diva campaign the NSF-funded grant to ACM and WGBH-Boston

7 And it was a year that introduced major enhancements to the crown jewel

8 Sophisticated improvements to the citation pages

9 I am particularly pleased to report that it was a year ACM and the IEEE-Computer

10 The IEEE-Computer Society began to explore myriad ways the two organizations might work together.

Exercício 8: Agora vamos observar os gráficos do COCA. Onde o TO é mais frequente?

\begin{tabular}{l|c|c|c|l}
\hline $\begin{array}{l}\text { SECTION (CLICK FOR SUB-SECTIONS) } \\
\text { (SEE ALL SECTIONS AT ONCE) }\end{array}$ & FREQ & SIZE (M) & PER MIL & CLICK FOR CONTEXT (SEE ALL) \\
\hline SPOKEN & $2,975,064$ & 109.4 & $27,196.45$ & \\
\hline FICTION & $2,511,014$ & 104.9 & $23,937.03$ & \\
\hline MAGAZINE & $2,748,925$ & 110.1 & $24,965.12$ & \\
\hline NEWSPAPER & $2,601,274$ & 106.0 & $24,548.69$ & \\
\hline ACADEMIC & $2,635,803$ & 103.4 & $25,485.91$ & \\
\hline & & & & \\
\hline
\end{tabular}


Exercício 9: Agora que já estudamos alguns colocados, vamos ao programa AntConc, baixe o programa neste endereço: http://www.antlab.sci.waseda.ac.jp/software.html, abra o arquivo em txt das letras de música de seu cantor favorito e cheque a palavra FOR na seção CLUSTERS (colocados). Quais palavras acompanham com mais frequência esse item lexical? São as mesmas da música que estudamos? 0 que aparece de semelhante? 0 que aparece de diferente? Discuta com seus amigos e tome nota. Essa é uma ótima maneira de investigarmos a língua em uso e aprender um novo idioma de maneira eficaz.

Exercício 10: Agora que você já aprendeu, crie frases com FOR e TO:

Exercício 11: Word Clouds: Aqui estão frases de 2 bandas e 2 cantores: Madonna, Bon Jovi, Maroon 5 e Bruno Mars. Relacione a cloud com o(a) cantor(a) / banda:

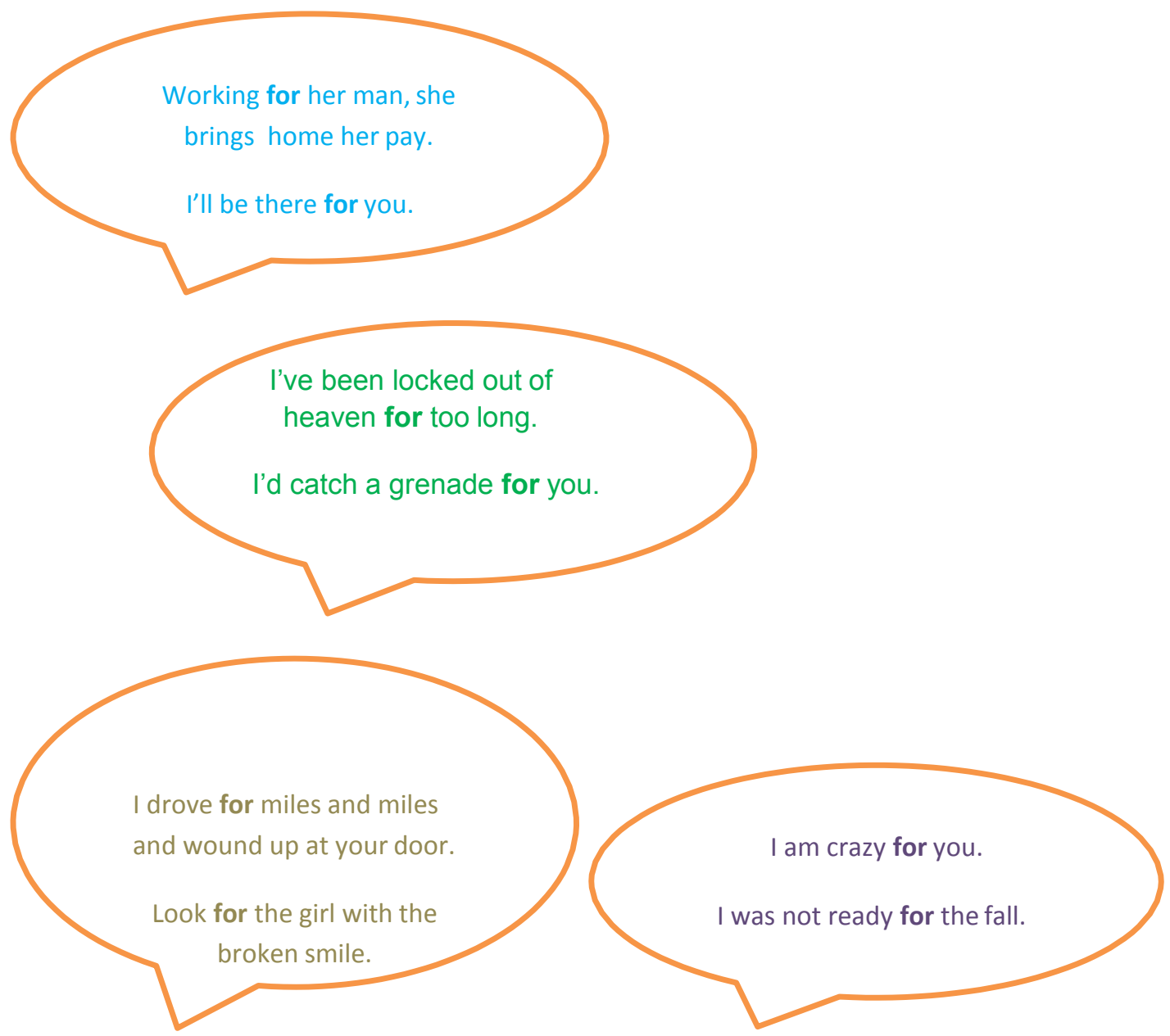


Exercício 12: Agora crie a sua própria "cloud" com 02 frases de músicas, contendo a palavra FOR:

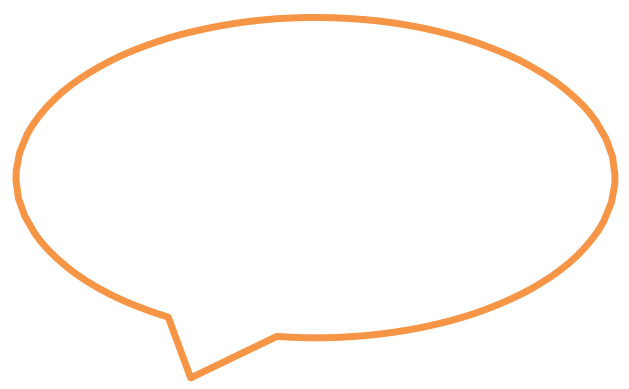

Exercício 13: Que tal agora cantarmos a música no nosso karaokê? Vamos ao endereço: http://www.youtube.com/watch?v=87jUZy78Up4

Recebido em 26 de setembro de 2019.

Aceite em 08 de dezembro de 2019.

Beatles: <http://www.beatleshp.com/»; Bon Jovi: <http://www.bonjovi.com/ ; Bruno Mars: $<$ http://www.brunomars.com/ $;$; Maroon 5: <http://www.vagalume.com.br/maroon-5/>. Acesso em: 5 jan. 2014.

ii Frequência normalizada = número de ocorrências da palavra no corpus $\div$ número de ocorrências do corpus $x$ base da normalização (1.000).

iii Destacamos alguns programas, como o AntConc, concordanciador gratuitamente disponível desenvolvido por Laurence Anthony, da Universidade de Waseda, no Japão, disponível em: $<$ http://www.laurenceanthony.net/software.html ; COCA (Corpus of Contemporary American English) é um corpus monitor da língua inglesa, disponível em: <http://corpus.byu.edu/ $>$; Sketch Engine possibilita o estudo do comportamento da língua através da pesquisa em grandes quantidades de textos, disponível em <https://www.sketchengine.co.uk/>. Acesso em: 5 dez. 2015. 